\title{
Effect of Serine Hydroxamate and Methyl a-D-glucopyranoside Treatment on Nucleoside Polyphosphate Pools, RNA and Protein Accumulation in Streptomyces hygroscopicus
}

\author{
By DIETER RIESENBERG, '* FRIEDRICH BERGTER' AND \\ CSABA KARI? \\ 'Akademie der Wissenschaften der DDR. Forschungszentrum für Molekularbiologie und \\ Medizin. Zentralinstitut für Mikrobiologie und experimentelle Therapie, Beutenbergstrasse II, \\ Schliessfach 73, DDR-6900 Jena, GDR \\ 'Institute of Genetics, Biological Research Center, Hungarian Academy of Sciences, \\ H-6701 Szeged, POB 521, Hungary'
}

(Receited 18 October 1983: retised 26 April 1984)

The accumulation of RNA and protein and the kinetics of nucleoside triphosphate and guanosine polyphosphate pools during amino acid starvation and carbon source downshift were investigated in Streptomyces hygroscopicus. RNA accumulation was controlled stringently during both amino acid starvation and carbon source downshift. The pool size of ppGpp increased dramatically under these conditions. However, the intracellular concentrations of nucleoside triphosphates were low and the concentration of guanosine polyphosphates was much lower than in Escherichia coli. The possible significance of this phenomenon in the regulation is discussed.

\section{INTRODUCTION}

In the preceding paper (Riesenberg \& Bergter, 1984), a method for obtaining balanced growth of Streptomyces hygroscopicus was described. Balanced growth lasted for at least two doublings of biomass. This method enabled us to investigate the regulation of growth under balanced conditions, and under imbalance induced by various treatments.

Escherichia coli growing in a balanced manner accumulates guanosine 3'-diphosphate 5'diphosphate (ppGpp) after perturbation, e.g. after amino acid starvation (Cashel \& Gallant, 1969). ppGpp mediates the stringent response, which includes cessation of RNA accumulation. A wide range of other processes is influenced by $\mathrm{ppGpp}$, which serves to re-orient the cell metabolism after metabolic shifts (Cashel, 1975; Nierlich, 1978; Gallant, 1979).

Similar regulatory patterns have been found in Klebsiella pneumoniae (Riesenberg \& Kari, 1981: Riesenberg et al., 1982) and Bacillus subtilis (Smith et al., 1980). Caulobacter crescentus (Chiaverotti et al., 1981) and Rhizobium meliloti (Belitsky \& Kari, 1982) exhibit different regulatory patterns.

The occurrence of ppGpp in streptomycetes has been well documented (Hamagishi et al., 1981). However, so far no effort has been made to investigate the stringent response and the possible role of ppGpp in a Streptomyces strain. Since we had worked out the conditions for balanced growth in $S$. hydroscopicus (Riesenberg \& Bergter, 1984), the possible involvement of ppGpp in regulation following various shifts could be studied. In this paper we present the characterization of accumulation of RNA, protein, nucleoside triphosphate and guanosine polyphosphate pools during amino acid starvation and carbon source downshift.

Abhretiations: $x$ MG, methyl $x$-D-glucopyranoside: SHX. DL-serine hydroxamate. 


\section{METHODS}

Organisms, media and culture conditions. Conditions for Strpptomy'ces hygroscopicus were given in the preceding paper (Riesenberg \& Bergter, 1984). Escherichia coli CP78 (arg his thr leu thi rel $A^{+}$), kindly supplied by Dr N. Fiil (Copenhagen), was also used in these studies. Medium and culture conditions for $E$. coli were those of Kari et al. (1977).

Chemicals. DL-Serine hydroxamate (SHX), methyl $\alpha$-D-glucopyranoside ( $\alpha \mathrm{MG)}$ ), yeast inorganic pyrophosphatase and 3 -nucleotidase were purchased from Sigma. Guanosine 5'-triphosphate 3-diphosphate (pppGpp), guanosine 5'-diphosphate 3'-diphosphate (ppGpp), guanosine 5'-tetraphosphate (ppppG), adenosine 5'triphosphate 3 -diphosphate (pppApp), adenosine 5 -diphosphate 3 -diphosphate (ppApp) and adenosine 5 tetraphosphate (ppppA) were obtained from ICN (Irvine, Calif., USA). Guanosine 5 'monophosphate 3'monophosphate (pGp) was supplied by P-L Biochemicals (Milwaukee. Wisconsin, USA). Guanosine 5 'triphosphate (GTP), adenosine 5'-triphosphate (ATP), cytidine 5'-triphosphate (CTP), uridine 5 '-triphosphate (UTP) and guanosine 5 -monophosphate (pG) came from Serva (FRG). Polyethyleneimine impregnated sheets (PEI and PEI-UV ${ }_{254}$ ) were manufactured by Macherey \& Nagel Co. (Düren. FRG). DEAE-A25 was from Pharmacia. $\mathrm{KH}_{2}{ }^{32} \mathrm{PO}_{4}$ (carrier-free) was supplied by Isocommerz (GDR). [8-3 $\mathrm{H}$ ]Guanosine (370 GBq $\mathrm{mmol}^{-1}$ ) and $\left[2-{ }^{3} \mathrm{H}\right]$ adenine $\left(925 \mathrm{GBq} \mathrm{mmol}{ }^{-1}\right)$ were purchased from Amersham and $[5-3 \mathrm{H}]$ uridine $\left(814 \mathrm{GBq} \mathrm{mmol}^{-1}\right)$ and L $f^{1+}$ Clleucine $\left(7.8 \mathrm{GBq} \mathrm{mmol}^{-1}\right)$ were obtained from UVVVR Prague (CSSR).

Identification of $p p p G p p$ and ppGpp. (i) Culturing and radioactive labelling. Spores of $S$. hygroscopicus were germinated and grown in $100 \mathrm{ml}$ flasks containing $35 \mathrm{ml}$ medium (with $0.15 \mathrm{mM}-\mathrm{KH}_{2} \mathrm{PO}_{4}$ ). Five ml was labelled with $11 \mathrm{MBq}^{3}{ }^{2} \mathrm{P}_{1} \mathrm{ml}^{-1}: 20 \mathrm{ml}$ received $74 \mathrm{kBq}^{32} \mathrm{P}_{1} \mathrm{ml}^{-1}$. After further incubation for one doubling, the culture with the lower ${ }^{32}$ P specific activity was distributed into three flasks as $5 \mathrm{ml} \mathrm{samples} \mathrm{for} \mathrm{double} \mathrm{labelling:} \mathrm{the} \mathrm{first}$ contained $\left[5 .{ }^{3} \mathrm{H}\right]$ uridine at $3 \mathrm{MBq}(3.7 \mathrm{nmol}) \mathrm{ml}^{-1}$, the second $\left[8-{ }^{3} \mathrm{H}\right] \mathrm{guanosine}$ at $2.8 \mathrm{MBq}(7.5 \mathrm{nmol}) \mathrm{ml}^{-1}$ and the third $\left[2 .{ }^{3} \mathrm{H}\right.$ )adenine at $0.9 \mathrm{MBq}(0.9 \mathrm{nmol}) \mathrm{ml}^{-1}$. After $7.5 \mathrm{~min}$ SHX $\left(2.5 \mathrm{mg} \mathrm{ml}^{-1}\right)$ was added to all cultures for induction of synthesis of pppGpp and ppGpp; $10 \mathrm{~min}$ after addition of SHX, all cultures were cooled in an ice bath.

(ii) Exsraction of cell pool. Nucleotides were extracted with $1 \mathrm{M}$-formic acid in an ice bath for $30 \mathrm{~min}$ (Cashel et al., 1969). After centrifugation of the extract, the supernatant was brought to $\mathrm{pH} 6.5$ to 7.4 with $\mathrm{NH}_{4} \mathrm{OH}_{\text {. A small }}$ sample of the neturalized extract from cultures labelled with $11 \mathrm{MBq}{ }^{32} \mathrm{P}_{1} \mathrm{ml}^{-1}$ was used for identification of nucleoside polyphosphates by thin layer co-chromatography, either with unlabelled UV-markers or with ${ }^{32} \mathbf{p}$. labelled extracts of $E$. coli. The nucleoside polyphosphates of the remainder and of the neutralized extracts derived from double-labelled cultures were concentrated on a Sephadex DEAE-A25 $\left(\mathrm{HCO}_{3}\right)$ column.

(iii) Column concentration of nucleotides. Each $5 \mathrm{ml}$ supernatant was added to $13 \mathrm{ml} \mathrm{H}_{2} \mathrm{O}$ and $8 \mathrm{ml}$ Sephadex DEAE-A25 $\left(\mathrm{HCO}_{3}^{-}\right.$) stock (2 vols $\mathrm{H}_{2} \mathrm{O}: 1$ vol. Sephadex). After adsorption of nucleotides (10 min at room temperature, with occasional stirring) the gel was washed three times with $20 \mathrm{ml} \mathrm{H}_{2} \mathrm{O}$. After final decantation the sediment was stirred with $10 \mathrm{ml} \mathrm{H}_{2} \mathrm{O}$ and then transferred to a column. The column was prewashed with $8 \mathrm{ml}$ 0.2 M-triethylammonium bicarbonate and then the nucleotides were eluted with $8 \mathrm{ml} 1$ M-triethylammonium bicarbonate. The eluates were evaporated under reduced pressure at $30^{\circ} \mathrm{C}$. For complete removal of triethylammonium bicarbonate, evaporation was repeated four times using $50 \%(v / v)$ alcohol. Finally, the samples were dissolved in $200 \mu \mathrm{l} \mathrm{H}_{2} \mathrm{O}$.

The sample derived from the culture labelled with $11 \mathrm{MBq}{ }^{32} \mathrm{P}_{1} \mathrm{ml}^{-1}$ was applied to a second DEAEA25 $\left(\mathrm{HCO}_{3}\right.$ ) column for separation of tentative pppGpp and ppGpp (see below).

The samples derived from ${ }^{32} \mathrm{P} /{ }^{3} \mathrm{H}$ labelled cultures were freeze-dried, dissolved in $20 \mu \mathrm{l} \mathrm{H}_{2} \mathrm{O}$ and then used for thin layer chromatography (see below).

(iv) Thin layer chromatography for the identification of nucleoside polyphosphates. Two-dimensional resolution of nucleoside polyphosphates was achieved in the system of Cashel \& Kalbacher (1970) (3.3 M-ammonium formate and $4.2 \%$ boric acid in the first dimension; $1.5 \mathrm{M}-\mathrm{KH}_{2} \mathrm{PO}_{4}$ in the second dimension) and the system of $\mathrm{Pao} \&$ Gallant (1979) (4 $\mathrm{M}$-formic acid and $1 \mathrm{M}$-lithium chloride in the first dimension: $1.5 \mathrm{M}-\mathrm{KH}_{2} \mathrm{PO}_{4}$ in the second dimension). Samples of $\mathbf{4 0} \mu \mathrm{l}$ of neutralized formic acid extracts derived from cultures of $S$. hygroscopicus labelled with $11 \mathrm{MBq}^{32} \mathrm{P}_{1} \mathrm{ml}^{-1}$ were applied to each PEI-UV $\mathrm{V}_{4}$ plate $(20 \times 20 \mathrm{~cm})$. The following UV-markers served for co-chromatography: pppGpp, ppGpp, ppppG, pppApp, ppApp, ppppA, GTP, ATP, CTP and UTP. Samples of $10 \mu 1$ neutralized formic acid extracts of ${ }^{32}$ P-labelled cells of $E$. coli CP78 were also applied for cochromatography. The extracts were prepared as described by Török Kari (1980). Nucleoside polyphosphates of the ${ }^{32} \mathrm{P} /{ }^{3} \mathrm{H}$ labelled and column-concentrated samples of $S$. hygroscopicus were separated applying the system of Cashel \& Kalbacher (1970). After autoradiography the spots were cut out. Extraction of nucleotides, neutralization and quantification were done according to Török \& Kari (1980).

(v) Preparation of tentatice $p p p G p p$ and $p p G p p$ from $S$. hygroscopicus. The nucleoside polyphosphates of the column-concentrated 12 - P-labelled samples were separated by linear gradient elution for $25 \mathrm{~h}$ using DEAEA $25\left(\mathrm{HCO}_{3}^{-}\right)$column $(1.3 \times 10 \mathrm{~cm})$ and $400 \mathrm{ml} 0$ to $1 \mathrm{M}$-triethylammonium bicarbonate. The expected fractions of tentative pppGpp and ppGpp identified by co-chromatography of unlabelled pppGpp and ppGpp (see above) 
were concentrated by evaporation and were freeze-dried as described above.

(vi) Enzyme treatments. In a modification to the method of Sy \& Lipmann (1973), tentative pppGpp and ppGpp of $S$. hygroscopicus were treated with yeast inorganic pyrophosphatase and 3 -nucleotidase. A $100 \mu l$ portion of $15 \mathrm{~mm}$-Tris/ $\mathrm{HCl}$ (pH 7.2) containing $2 \mathrm{~mm}-\mathrm{ZnCl}$, and 20 units of yeast inorganic pyrophosphatase (solution 1 ) was added to freeze-dried samples of pppGpp and $\mathrm{ppGpp}$, and the mixture incubated at $37^{\circ} \mathrm{C}$ for $30 \mathrm{~min}$. In a second experiment, $100 \mu \mathrm{l} 15 \mathrm{~mm}$-Tris/ $\mathrm{HCl}(\mathrm{pH} \mathrm{7.2)}$ containing $2 \mathrm{~mm}-\mathrm{ZnCl}, 20$ units of yeast inorganic pyrophosphatase and 0.01 units of $3^{\prime}$-nucleotidase (solution 2) was added to freeze-dried samples and the mixture incubated at $37^{\circ} \mathrm{C}$ for $4 \mathrm{~h}$. Samples $(20 \mu \mathrm{l})$ before and after incubation were applied to PEI-UV $\mathbf{s}_{4}$ plates. The PEI plate with samples of solution 1 was co-chromatographed together with pGp as a UV-marker in $0.75 \mathrm{M}-\mathrm{KH}_{2} \mathrm{PO}_{4}$. pH 3.4 (Cashel $\mathrm{et}$ al ., 1969). Samples of solution 2 were run together with $p G$ as a UV-marker, according to Randerath \& Randerath (1964).

Determination of accumulation of RNA and protein. Cultures were double labelled according to Riesenberg \& Kari (1981) with minor modifications. The incorporation of $\left[{ }^{1+C}\right]$ leucine and $\left[{ }^{3} \mathrm{H}\right]$ uridine $\left[9 \cdot 3 \mathrm{KBq}(41 \mathrm{nmol}) \mathrm{ml}^{-1}\right.$ and $185 \mathrm{KBq}(20 \mathrm{nmol}) \mathrm{ml}^{-1}$, respectively) into material precipitable by ice-cold $5_{\mathrm{a}}^{\circ}$ trichloracetic acid was followed by filtration and washing of $0.1 \mathrm{ml}$ samples (Whatman GF/C filters). Radioactivities were measured in a Packard Tricarb liquid scintillator and corrected for spill over $\left(16^{\circ}{ }_{\circ}\right.$ of ${ }^{14} \mathrm{C}$ into the ${ }^{3} \mathrm{H}$-channel and $0.5^{\circ} \%$ of ${ }^{3} \mathrm{H}$ into the ${ }^{1+}$ (-channel).

Determination of nucleoside polyphosphate pools. Spores of $S$. hygroscopicus were germinated and grown in tubes containing $5 \mathrm{ml}$ medium (with $0.15 \mathrm{mM}-\mathrm{KH}_{2} \mathrm{PO}_{4}$ ). After two doublings of biomass the culture was labelled with $14.8 \mathrm{MBq}^{3}: \mathrm{P}_{1} \mathrm{ml}^{-1}$. After a further doubling to equilibrate the pool, SHX or $\alpha \mathrm{MG}$ was added. At the times indicated in the figures, samples $(100 \mu \mathrm{l})$ were withdrawn, extracted at 0 to $4^{\circ} \mathrm{C}$ in $\mathrm{I} \mathrm{M}$-formic acid for $30 \mathrm{~min}$ and then centrifuged. A sample of $50 \mu \mathrm{l}$ of the formic acid extract was applied to PEI-plates in portions of $10 \mu \mathrm{l}$, with intermediate drying, and chromatographed with $0.75 \mathrm{M}-\mathrm{KH}_{2} \mathrm{PO}_{4}(\mathrm{pH} 3.4)$ for separation of ATP, CTP and UTP, and with $1.5 \mathrm{M}-\mathrm{KH}_{2} \mathrm{PO}_{4}(\mathrm{pH} \mathrm{3.4)}$ for separation of pppGpp. ppGpp and GTP. After autoradiography the spots were cut out and radioactivity was measured in a counter. The pool sizes were expressed as pmol ( $\mathrm{mg}$ dry wt $)^{-1}$.

\section{RESULTS}

\section{Identification of pppGpp and $p p G p p$ from $S$. hygroscopicus}

After inducing the accumulation of nucleoside polyphosphates by treatment with SHX, pppGpp and ppGpp were identified on the basis of the following criteria.

(i) Co-chromatography with standard UV-markers. The tentative "P-labelled spots of $S$. hygroscopicus were located at the same position on the chromatograms as the unlabelled UV. markers pppGpp and ppGpp after two-dimensional chromatography (Fig. $\mid a, b$ ). Control markers such as pppApp, ppApp, ppppA. GTP, ATP, CTP and UTP did not co-migrate with pppGpp and ppGpp in the systems of Cashel \& Kalbacher (1970) and Pao \& Gallant (1979). In addition, ppppG moved more slowly in the first dimension of the system of Cashel $\&$ Kalbacher (1970) than the 3:P-labelled ppGpp spot of $S$. hygroscopicus.

(ii) Co-chromatography with ${ }^{32}$ P-labelled markers from $E$. coli. Neutralized formic acid extracts from ${ }^{32} \mathrm{P}$-labelled cultures of $E$. coli and of $S$. hygroscopicus were chromatographed separately and together. pppGpp and ppGpp of $E$. coli moved to the same position as the respective spots of $S$. hygroscopicus. Quantification of the spots from common and separate running confirmed the co-migration.

(iii) Labelling with purine and pyrimidine precursors. Cultures of $S$. hygroscopicus were labelled with low specific activity ${ }^{32} \mathrm{P}_{\mathrm{i}}$ to detect nucleoside polyphosphates on autoradiograms after chromatography, and with high specific activity $\left[{ }^{3} \mathrm{H}\right]$ purine- and $\left[{ }^{3} \mathrm{H}\right]$ pyrimidine precursors to identify the nature of the nucleic acid bases (see Methods). The spots of $S$. hygroscopicus co-migrating with unlabelled pppGpp and ppGpp could be labelled with [8$\left.{ }^{3} \mathrm{H}\right]$ guanosine, but not with $\left[2-{ }^{3} \mathrm{H}\right]$ adenine and $\left[5-{ }^{3} \mathrm{H}\right]$ uridine. The spot located at the same position as unlabelled GTP was labelled with $\left[8-^{3} \mathrm{H}\right]$ guanosine, but not with $\left[2-{ }^{3} \mathrm{H}\right]$ adenine and $\left[5^{3} \mathrm{H}\right]$ uridine. The ATP spot contained label of $\left[2-^{3} \mathrm{H}\right]$ adenine and $\left[8-{ }^{3} \mathrm{H}\right]$ guanosine but not of $\left[5-{ }^{3} \mathrm{H}\right]$ uridine. The UTP- and CTP-control spots were labelled only by $\left[5-{ }^{3} \mathrm{H}\right]$ uridine.

(iv) Enzymic hydrolysis of spots co-migrating with (p)ppGpp. Tentative ${ }^{32} \mathbf{P}_{1}$-labelled pppGpp and ppGpp were completely converted into $\mathrm{pGp}$ by treatment with $\mathrm{Zn}^{2+}$-activated inorganic pyrophosphatase from yeast. The hydrolysed labelled compound moved to the same position on the chromatogram as unlabelled pGp-UV-marker. In reaction mixtures which contained 3 '-nucleotidase and inorganic pyrophosphatase, the tentative ${ }^{32}$ P-labelled pppGpp 

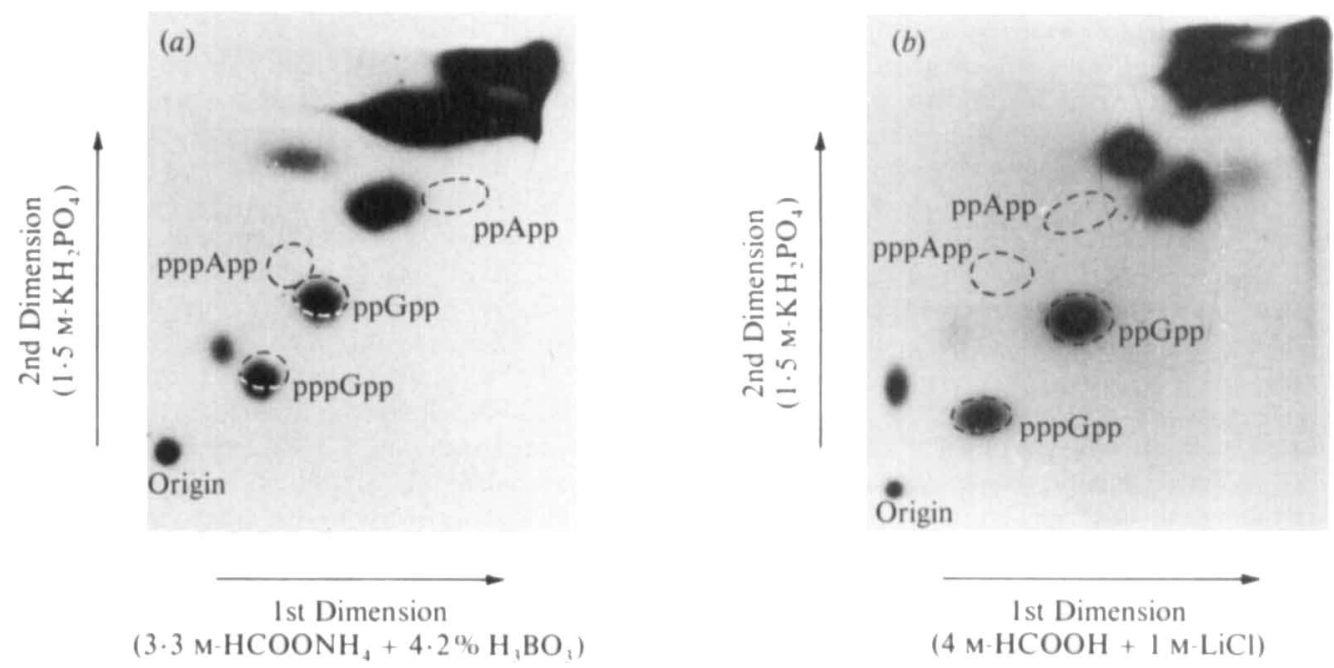

Fig. 1. Combined autoradiogram and fluorogram of formic acid extracts of 32 P-labelled and SHXtreated mycelia of $S$. hygroscopicus and of unlabelled UV-markers pppGpp, ppGpp, pppApp, ppApp (spots marked by dotted line), after two-dimensional chromatography according to (a) Cashel \& Kalbacher (1970), and (b) Pao \& Gallant (1979). Experimental conditions are described in Methods.

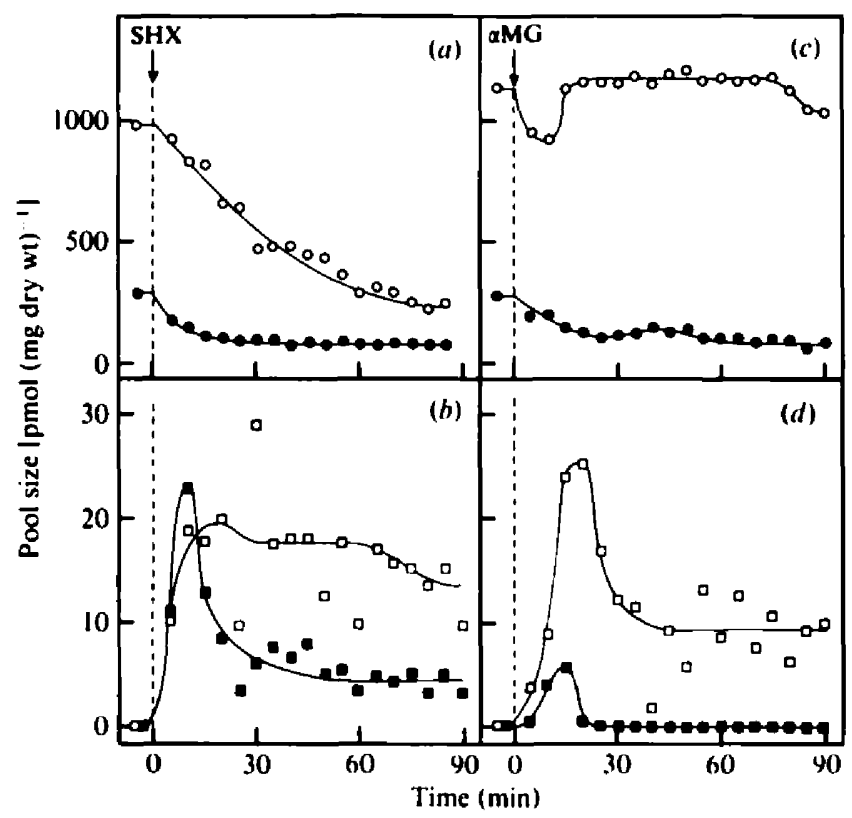

Fig. 2. Effect of SHX treatment $(a, b)$ and $\alpha$ MG treatment $(c, d)$ on pools of ATP (O), GTP (O), ppGpp $(\square)$ and pppGpp $(\square)$ pools in $S$. hygroscopicus. Experimental details are described in Methods.

and ppGpp were completely degraded to $\mathrm{pG}$ on the basis of co-chromatography with unlabelled pG-UV-marker (for experimental details see Methods). The enzymic tests proved that a pyrophosphoryl group was present in the 3'-position of guanosine 5'-triphosphate and of guanosine 5'-diphosphate. We concluded therefore, that $S$. hygroscopicus contained both pppGpp and ppGpp. 


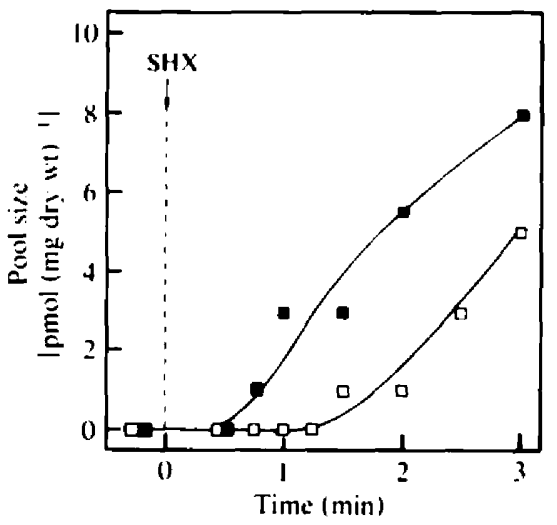

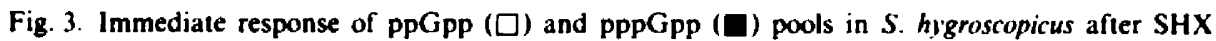
treatment. Experimental details are described in Methods.

Effect of SHX treatment on nucleoside polyphosphate pools, and RNA and protein accumulation

Accumulation of pppGpp and ppGpp occurred quickly after addition of SHX (2.5 mg ml-1) to exponentially growing mycelia of $S$. hygroscopicus (Fig. 2). The pool of pppGpp increased earlier than that of ppGpp (Fig. 3). The maximum concentration of pppGpp was reached about $10 \mathrm{~min}$ after SHX addition (Fig. 2). The peak was sharp, followed by a relatively rapid decrease. A plateau was established about $50 \mathrm{~min}$ after the treatment. ppGpp reached a plateau $20 \mathrm{~min}$ earlier, and no sharp peak was observed. The plateau levels of pppGpp and ppGpp were very low, i.e. 5 and $18 \mathrm{pmol}\left(\mathrm{mg} \text { dry } \mathrm{wt}^{-1}\right)^{-1}$. No pppGpp and ppGpp could be measured in samples from exponentially growing mycelium, although faint spots could be seen on the autoradiographic films.

The pool sizes of all four ribonucleoside triphosphates decreased after SHX-treatment. The pool size of ATP decreased slowly but continuously from $1000 \mathrm{pmol}$ ( $\mathrm{mg}$ dry wt) $)^{-1}$ to about 250 pmol during $90 \mathrm{~min}$ (Fig. 2). The pool size of GTP of exponentially growing mycelium amounted to about one-third of that of ATP. In contrast to ATP, the GTP pool decreased quickly; the pool size decreased to $50 \%$ of its original value after $10 \mathrm{~min}$ of SHX action. The GTP pool became constant at $25 \%$ of its initial value after $40 \mathrm{~min}$ (Fig. 2). The decrease in the GTP pool [more than 200 pmol (mg dry wt $)^{-1}$ ] was greater than the increase of pppGpp and ppGpp pools [less than $50 \mathrm{pmol}(\mathrm{mg} \text { dry wt })^{-1}$ ]. The pool size of CTP of exponentially growing mycelia was about $200 \mathrm{pmol}(\mathrm{mg} \text { dry wt })^{-1}$ and the pool size of UTP was about $260 \mathrm{pmol}(\mathrm{mg}$ dry wt $)^{-1}$. The kinetics of the CTP pool size after SHX treatment resembled that of GTP; $40 \mathrm{~min}$ after SHX treatment the new level of CTP was about $40 \%$ of the control value. The UTP pool decreased rapidly after addition of SHX, reaching a minimum of about $20 \%$ of the control pool size after $20 \mathrm{~min}$. Subsequently, the pool size increased slowly, reaching about $65 \%$ of the control level after 70 min (data not shown).

Accumulation of RNA and protein stopped after treatment of the culture with SHX (Fig. 4). This stringent control was relieved by simultaneous addition of SHX $\left(2.5 \mathrm{mg} \mathrm{ml}^{-1}\right)$ and chloramphenicol $\left(0.2 \mathrm{mg} \mathrm{ml}^{-1}\right)$ (data not shown). The intensity of the light scattered by the culture as a measure of biomass remained constant immediately after addition of SHX. The small increase $30 \mathrm{~min}$ later was probably due to changes in mycelial morphology, since microscopic observation revealed that the mycelia showed a tendency to fragment.

\section{Effect of $\propto M G$ treatment}

The response of $S$. hygroscopicus to carbon source shift down, imposed by $\alpha M G$ treatment of a glucose-grown culture, was an immediate accumulation of ppGpp (Fig. 2). The peak of the pool 


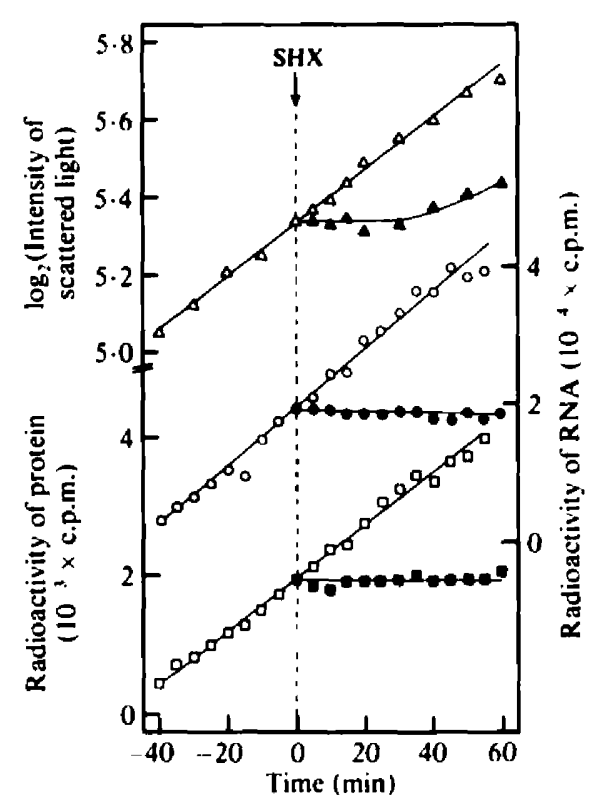

Fig. 4

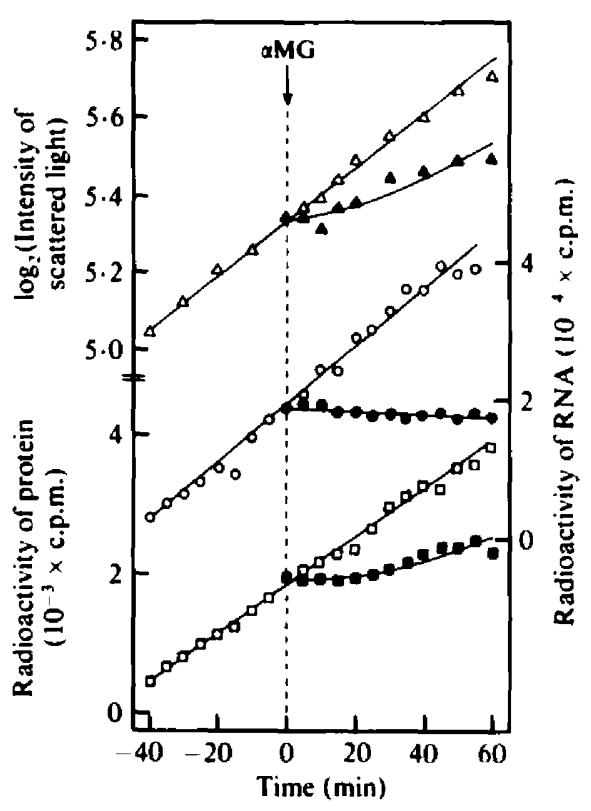

Fig. 5

Fig. 4. Effect of SHX treatment on accumulation of protein ( $\square$, control samples; $\square$, SHX-treated samples) and on intensity of scattered light as measure of biomass ( $\Delta$, control samples; $\Delta$, SHX-treated samples) and on accumulation of RNA (O, control samples;, , SHX-treated samples). Experimental details are described in Methods.

Fig. S. Effect of a MG treatment on accumulation of protein, RNA and intensity of scattered light as measure of biomass. Symbols are as for Fig. 4.

size was reached around 15 to 20 min after the onset of downshift. Thereafter, the ppGpp pool decreased, becoming constant after about $40 \mathrm{~min}$ of the downshift. The equilibrated post-shift level of ppGpp was very low, i.e. 10 pmol $\left(\mathrm{mg}_{\mathrm{g}} \mathrm{dry} \mathrm{wt}\right)^{-1}$. pppGpp was detected only in the first 15 min after shift down.

The pool sizes of ribonucleoside triphosphates ATP, GTP and CTP fell after addition of $\alpha$ MG, but, in contrast to SHX treatment, the ATP level decreased only slightly, i.e. to $80 \%$ of the control value $10 \mathrm{~min}$ after the shift. Thereafter, ATP returned to the control level (Fig. 2). The GTP pool, however, decreased continuously. The post-shift level was $50 \%$ of the control level after $15 \mathrm{~min}$ and reached the final level of $30 \%$ of control after $60 \mathrm{~min}$. The size of CTP also decreased after imposing the carbon source downshift. It reached a minimum (about $40 \%$ of control after $10 \mathrm{~min}$ ), then increased again until it became constant after about $50 \mathrm{~min}$ at $70 \%$ of the control (data not shown).

Accumulation of RNA and protein ceased immediately after addition of $\alpha$ MG (Fig. 5). After $20 \mathrm{~min}$, accumulation of protein recommenced, but at a much lower rate than before the shift. The values for intensity of scattered light indicated that growth continued after a lag period of $20 \mathrm{~min}$, but at a very reduced specific growth rate.

\section{DISCUSSION}

\section{Occurrence of nucleoside polyphosphates in S. hygroscopicus}

Streptomyces hygroscopicus accumulated ppGpp and pppGpp, in common with other streptomycetes (An \& Vining, 1978; Simuth et al., 1979; Hamagishi et al., 1980; Hamagishi et al., 1981: Nishino \& Murao, 1981 ; Stastna \& Mikulik, 1981). On the other hand, we could not find adenosine polyphosphates, which have been described for some other Streptomyces strains (Simuth et al., 1979; Hamagishi et al., 1981). This discrepancy could be due either to the 
organism or to different cultural conditions. We cannot exclude the possibility that adenosine polyphosphates are present in $S$. hygroscopicus at different stages of growth.

The concentration of (p)ppGpp in $S$. hygroscopicus during exponential growth was considerably lower than in S. griseus (An \& Vining, 1978), in S. aureofaciens (Simuth et al., 1979) and in $S$. galileus (Hamagishi et al., 1981). We could see only faint (p)ppGpp spots on the autoradiographic films which were not distinguishable from the background by measuring radioactivity. This difference in the basal level of (p)ppGpp between $S$. hygroscopicus and other Streptomyces strains might be due to strain peculiarities, to the entirely different cultivation conditions or to different stages of growth. In the case of $S$. hygroscopicus we used young nondifferentiated mycelia (see preceding paper). We suppose that the mycelia of $S$. galileus, $S$. aureofaciens and $S$. griseus contained already aged differentiated mycelia as well as young nondifferentiated cells. Perhaps these aged differentiated regions were restricted in growth and hence could accumulate (p)ppGpp, unlike the present study where pool sizes were determined under balanced growth.

\section{Effect of serine hydroxamate treatment on nucleoside polyphosphate pools, $R N A$ and protein accumulation}

SHX, an analogue of serine (Tosa \& Pizer, 1971), induces a stringent response in a variety of micro-organisms. Among these are E. coli (Tosa \& Pizer, 1971), K. pneumoniae (Riesenberg \& Kari, 1981), R. meliloti (Belitsky \& Kari, 1982) and B. subtilis (Belitsky \& Shakulov, 1980). SHX was also active in $S$. hygroscopicus. Its action resulted in an immediate cessation of accumulation of protein and RNA (Fig. 4), linked with rapid accumulation of (p)ppGpp (Figs 2 and 3). This is the first case where stringency in streptomycetes has been induced and shown to be connected with accumulation of (p)ppGpp. We conclude that $S$. hygroscopicus controls RNA accumulation during amino acid starvation stringently, like most other bacterial species. Caulobacter crescentus seems to be an exception in this respect since during amino acid starvation it did not accumulate (p)ppGpp and RNA synthesis continued (Chiaverotti et al., 1981). Rhizobium meliloti is another exception. It controlled RNA accumulation during amino acid starvation stringently but without concomitant accumulation of (p)ppGpp (Belitsky \& Kari, 1982).

In $S$. hygroscopicus the inhibition of RNA accumulation during SHX treatment was not due to inhibition of protein synthesis or any side effect of SHX because the simultaneous addition of chloramphenicol relieved the SHX inhibition of RNA accumulation. Whether $S$. hygroscopicus shows the other characteristics of stringent response, known from $E$. coli, has yet to be demonstrated. The experimental system described in the preceding paper (Riesenberg \& Bergter, 1984) is suitable for such investigations.

The pool size of pppGpp increased earlier than that of ppGpp after SHX treatment (Fig. 3). This is in agreement with the general opinion that pppGpp is the precursor of ppGpp. We conclude that $S$. hygroscopicus most probably uses the same pathway for deriving ppGpp as $E$. coli (Kari et al., 1977). The rapid decrease of the GTP pool after SHX treatment supported the opinion that GTP is a precursor of pppGpp in S. hygroscopicus, as has been found for E. coli. But GTP was converted to something other than only pppGpp, since the GTP level decreased by more than $200 \mathrm{pmol}(\mathrm{mg} \mathrm{dry} \mathrm{wt})^{-1}$, whereas the two guanosine polyphosphates together never increased by more than $50 \mathrm{pmol}(\mathrm{mg} \text { dry } \mathrm{wt})^{-1}$.

Since SHX treatment led to a decrease of all four ribonucleoside triphosphate pools concomitant with a significant inhibition of macromolecular synthesis we conclude that amino acid starvation resulted in an inhibition of nucleotide synthesis in $S$. hygroscopicus as in $E$. coli (Cashel \& Gallant, 1968). However, the decrease of ATP and GTP pool in S. hygroscopicus after amino acid starvation, by a factor of about four, is more severe than in $E$. coli or any other bacteria investigated so far. In $B$. subtilis, GTP was the only triphosphate which decreased, also by about a factor of four, during amino acid starvation (Gallant \& Margason, 1972). Whether the behaviour of the ATP pool during the stringent response is a characteristic property of only $S$. hygroscopicus, or of the other streptomycetes as well, remains to be determined. 
Effect of $\alpha M G$ on nucleoside polyphosphate pools, RNA and protein accumulation

$\alpha \mathrm{MG}$ has been used successfully in $E$. coli for induction of carbon source downshift (Hansen $e t$ $a l ., 1975)$. It is an analogue of glucose which inhibits glucose uptake and accumulates as nonmetabolizable $\alpha$ MG-6-phosphate (Kessler \& Rickenberg, 1963). $\alpha$ MG has been found to be active also in $K$. pneumoniae (Riesenberg \& Kari, 1981). It also works in $S$. hygroscopicus (Figs 2 and 5). The general characteristics of the $\alpha M G$ downshift seemed to be similar to that of $E$. coli (Hansen $e t$ al., 1975) and of $K$. pneumoniae (Riesenberg \& Kari, 1981), i.e. both RNA and protein accumulation were curtailed, pppGpp accumulated rapidly, and after a transient appearence diminished to the basal level, whereas the ppGpp pool increased significantly. Therefore in Streptomyces, ppGpp may play a similar regulatory role during downshift as in other bacteria.

\section{Comparison of pool sizes of nucleoside polyphosphates of S. hygroscopicus and E. coli}

An important difference between $S$. hygroscopicus and $E$. coli became apparent by comparing the pool size of ppGpp after induction of the stringent response or after imposing carbon source downshift. The equilibrated pool size of ppGpp after the stringent response was about 0.5 to $1 \mathrm{mM}$ in $E$. coli (Nierlich, 1978). For comparison, we converted these data into pmol (mg dry wt $)^{-1}$ and obtained 1500 to $3000 \mathrm{pmol}$. We assumed for $E$. coli growing in glucose/mineral salts medium a doubling time of $45 \mathrm{~min}$, mean cell length, $L, 2.62 \mu \mathrm{m}$, mean cell diameter, $2 R$, $0.62 \mu \mathrm{m}$ (Grover et al., 1977), mean cell mass, $M, 0.264 \times 10^{-6} \mu \mathrm{g}$ (Günther \& Bergter, 1971). This means that the pool size of ppGpp in $S$. hygroscopicus [18 pmol (mg dry wt) ${ }^{-1}$, see Fig. 2] was about 100-fold lower than in E. coli.

The comparison was also made for the pool sizes of ATP and GTP of exponentially growing $E$. coli and $S$. hygroscopicus. We converted (as described above) the intracellular concentrations of ATP (I to $2 \mathrm{mM}$ ) and of GTP (0.3 to $1 \mathrm{~mm}$ ) published by Nierlich (1978) for E. coli into 3000 to $6000 \mathrm{pmol}$ ATP (mg dry wt) ${ }^{-1}$, and 900 to $3000 \mathrm{pmol}^{\mathrm{GTP}}$ (mg dry wt) ${ }^{-1}$. The ATP pool and GTP pool of S. higroscopicus with about 1000 and $300 \mathrm{pmol}(\mathrm{mg} \text { dry wt) })^{-1}$ were about fivefold lower than in $E$. coli. With a bioluminescent assay, similar ATP pools were determined in exponentially growing mycelium of $S$. aureofaciens $\left[300 \mathrm{pmol}(\mathrm{mg} \text { dry } w \mathrm{t})^{-1}\right.$ (Curdova et al., 1976)], of $S$. fradiae [1500 $\mathrm{pmol}$ (mg dry wt) ${ }^{-1}$ (Vu-Trong et al., 1980)] and of $S$. noursei [330 pmol ( $\mathrm{mg}$ dry $w t)^{-1}$, (F. Hänel, personal communication)]. Only streptomycetes derived from the above-mentioned strains with improved antibiotic production exhibited a significantly lower ATP pool during exponential growth (Curdova et al., 1976; F. Hänel, personal communication).

This lower ATP pool size of exponentially growing mycelium of $S$. hygroscopicus was not due to an incomplete extraction procedure since extraction with $0.1 \mathrm{M}-1,1 \mathrm{M}$ - and $2.5 \mathrm{M}$-formic acid revealed no significantly different pool sizes. The lower content of nucleoside triphosphates in $S$. hygroscopicus compared to $E$. coli might be due to the diversity of these unrelated bacteria.

The most striking result was that during stringent response, the ppGpp pool in $S$. hygroscopicus was about 100-fold lower than in E. coli. The mycelia of $S$. hygroscopicus used in these studies were derived from spores and were not yet differentiated. This means that each hyphal part of the mycelia synthesized DNA, RNA and protein to the same extent. This has been shown autoradiographically for synthesis of DNA (C. Kummer, personal communication). Since all mycelial parts seemed to be metabolically active, one can assume that the analogues used acted everywhere in the mycelium. Therefore, the very low ppGpp pool during the stringent response cannot be explained by a restriction of parts of the mycelium (e.g. apexes) capable of ppGpp synthesis. From this we conclude that if ppGpp is indeed involved in the stringent control in $S$. hygroscopicus as it is in many other bacteria, then the target molecule should be very sensitive towards ppGpp.

The authors gratefully acknowledge the technical assistance of Mrs Jutta Günther. 


\section{RE FER E NCES}

AN, G. \& VINING, L. C. (1978). Intracellular levels of guanosine 5 -diphosphate 3 -diphosphate (ppGpp) and guanosine 5'-triphosphate 3 -diphosphate (pppGpp) in cultures of Streptomyces griseus producing streptomycin. Canadian Journal of Microbiology. 24. $502-511$.

Belitsky, B. \& KARI, C. (1982). Absence of accumulation of ppGpp and RNA during amino acid starvation in Rhizobium meliloti. Journal of Biological Chemistry 257, 46774679.

Belitsky, B. R. \& Shakulov, R. S. (1980). Amount of guanosine polyphosphate and the level of stable RNA synthesis in Bacillus subtilis cells upon inhibition of protein synthesis. Molekulyarnaya Biologiya 14. 1343 1353. (in Russian).

CASHEL. M. (1975). Regulation of bacterial ppGpp and pppGpp. Annual Reriew of Genetics 29. 301318.

Cashel, M. \& Gallant, J. (1968). Control of RNA synthesis in E. coli. I. Amino acid dependence on the synthesis of the substrates of RNA polymerase. Journal of Molecular Biolog. 34, 317-330.

Cashel. M. \& Gallant, J. (1969). Two compounds implicated in the function of the RC gene of Escherichia coli. Nature, London 221. 838-841.

CASHel, M. \& Kalbacher, B. (1970). The control of ribonucleic acid synthesis in Escherichia coli. V. Characterization of a nucleotide associated with the stringent response. Journal of Biological Chemistry 245. $2309-2318$.

Cashel, M., Lazzarini, R. A. \& Kalbacher, B. (1969). An improved method for thin-layer chromatography of nucleotide mixtures containing $3: \mathrm{P}$. labeled orthophosphate. Journal of Chromatography. 40. 103-109.

Chiaverotti. T. A., Parker, G., Gallant, J. \& Agabian. N. (1981). Conditions that trigger guanosine tetraphosphate accumulation in Caulobacter crescentus. Journal of Bacteriology 145, 14631465.

Curdova, E., Kremen, A., Vanek, Z \& Hostalek. Z. (1976). Regulation and biosynthesis of secondary metabolites. XVIII. Adenylate level and chlorotetracycline production in Sireptomyces aureofaciens. Folia microbiologica 21, $481-487$.

Gallant, J. (1979). Stringent control in E. coli. Annual Review' of Genetics 13,393. 415.

Gallant, J. \& Margason, G. (1972). Amino acid control of messenger ribonucleic acid synthesis in Bacillus subtilis. Journal of Biological Chemistry 247. 2289-2294.

Grover, N. B., Woldringh, C. L., Zaritsky, A. \& ROSENBERGER. R. F. (1977). Elongation of rodshaped bacteria. Journal of Theorefical Biology 67. 181-193.

Gïnther, H. H. \& Bergter, F. (1971). Bestimmung der Trockenmasse von Zellsuspensionen durch Extinktionsmessungen. Zeilschrifi für Allgemeine Mikrobiologie 11. 191-197.

Hamagishi. Y., Yoshimoto. A.. OKI, T. \& invi. T. (1980). Occurrence of guanosine-5'-diphosphate- 3 'diphosphate and adenosine-5'-triphosphate-3'-diphosphate in Streptomyces galilaeus. Agricultural and Biological Chemistry 44, 1003-1007.

Hamagishi, Y., Yoshimoto, A. \& OKI, T. (1981).
Determination of guanosine tetraphosphate (ppGpp) and adenosine pentaphosphate (pppApp) in various microorganisms by radioimmunoassay. Archices of Microbiology' 139, 134137.

hansen, M. T., Pato, M. L. Molin, S.. Fill, N. P. \& Von MEyenbuRg. K. (1975). Simple downshift and resulting lack of correlation between ppGpp pool size and ribonucleic acid accumulation. Journal of Bacteriology 122, 585-591.

KarI. C., TöröK, I. \& Travers. A. (1977). ppGipp cycle in Escherichia coli. Molecular and General Genetics 150, 249255.

Kessler, D. P. \& Rickenberg. H. V. (1963). The competitive inhibition of $x$-methyl glucoside uptake in Escherichia coli. Biochemical and Biophysical Research Communications 10. 482487.

NierLich, D. P. (1978). Regulation of bacteria] growth, RNA, and protein synthesis. Annual Reriew of Microbiology 32, 393.432.

Nishino. T.\& MLrao. S. (1981). Possible involvement of plasmid in nucleotide pyrophosphokinase production and the relationship between this productivity and cellular accumulation of guanosine tetraphosphate (ppGpp) in Streptomycetes. Agricultural and Biological Chemistry 45, 199-208.

Pao, C. C. \& Gallant. J. (1979). A new nucleotide involved in the stringent response in Escherichia coli. Journal of Biological Chemistry 254, 688 692.

Randerath. K. \& Randerath. F. (1964). Ionexchange chromatography of nucleotides on poly(ethyleneimine)-cellulose thin layers. Journal of Chromalography 16, 111125.

RIESENBERG, D. \& Bergter, F. (1984). Establishment of a system suitable for analysis of balanced and unbalanced growth of Sireptomices higroscopicus. Journal of General Microbiology 130. 2543 2548.

RIESENBERG, D. \& KARt, C. (1981). Isolation and characterization of prototrophic relaxed mutants of Klehsiella pneumoniae. Molecular and General Generics 181, 476483.

Riesenterg, D., Frdei. S., Kondorosi. F. \& Kari, C. (1982). Positive involvement of ppGipp in derepression of the nif operon in Klebsiella preumoniae. Molecular and General Genetics 185, 198-204.

Simlth, J., Hudec, J., Chau, H. T.. Danyi, O. \& ZeLiNkA. J. (1979). The synthesis of highly phosphorylated nucleotides. RNA and protein by Sireptomyces aureofaciens. Journal of Antibiotics 32. 53-58.

Smith. I.. Paress. P., Cabane, K. \& Dubnal, E. (1980). Genetics and physiology of the rel system of Bucillus subtilis. Molecular and General Genetics 178, 271279.

Stastsa, \}. \& Mikclik, K. (1981). Role of highly phosphorylated nucleotides and antibiotics in the development of Streptomycetes. In Actinomycetes, pp. 481 486. Edited by K. P. Schaal \& G. Pulverer Stutlgart \& New York: Gustav Fischer Verlag.

SY, J. \& LipMaNN. F. (1973). Identification of the synthesis of guanosine tetraphosphate (MSI) as insertion of a pyrophosphoryl group into the 3 . position in guanosine 5 -diphosphate. Proceedings of the National Academy of Sciences of the United States of America 70. 306-309. 
TöRök. I. \& KARI, C. (1980). Accumulation of ppGpp in a relA mutant of $E$. coli during amino acid starvation. Journal of Biological Chemistry 255, 38383840.

TosA, T. \& Pizer, L. I. (1971). Biochemical bases for the antimetabolic action of $L$-serine hydroxamate. Journal of Bacteriology 106, 972-982.
Vu-Trong, K., Bhuwapathanapun, S. \& Gray, P. P. (1980). Metabolic regulation in tylosin-producing Streptomyces fradiae: Regulatory role of adenylate nucleotide pool and enzymes involved in biosynthesis of tylonolide precursors. Antimicrobial Agents and Chemotherapy 17, 519-525. 